\title{
What Is Career Success for Academic Hospitalists? A Qualitative Analysis of Early-Career Faculty Perspectives
}

\author{
Ethan Cumbler, MD, FHM, FACP'*, Essey Yirdaw, MPH'1, Patrick Kneeland, MD'1, Read Pierce, MD', \\ Patrick Rendon, $\mathrm{MD}^{2}$, Carrie Herzke, MD, SFHM, FAAP, FACP ${ }^{3}$, Christine D. Jones, MD'
}

${ }^{1}$ Division of Hospital Medicine, Department of Medicine, School of Medicine, University of Colorado, Aurora, Colorado; ${ }^{2}$ Division of Hospital Medicine, Department of Medicine, School of Medicine, University of New Mexico, Albuquerque, New Mexico; ${ }^{3}$ Division of General Internal Medicine, Department of Medicine, School of Medicine, Johns Hopkins University, Baltimore, Maryland.

BACKGROUND: Understanding the concept of career success is critical for hospital medicine groups seeking to create sustainably rewarding faculty positions. Conceptual models of career success describe both extrinsic (compensation and advancement) and intrinsic (career satisfaction and job satisfaction) domains. How hospitalists define career success for themselves is not well understood. In this study, we qualitatively explore perspectives on how early-career clinician-educators define career success.

METHODS: We developed a semistructured interview tool of open-ended questions validated by using cognitive interviewing. Transcribed interviews were conducted with 17 early-career academic hospitalists from 3 medical centers to thematic saturation. A mixed deductiveinductive, qualitative, analytic approach was used to code and map themes to the theoretical framework.

RESULTS: The single most dominant theme participants described was "excitement about daily work," which mapped to the job satisfaction organizing theme.
Participants frequently expressed the importance of "being respected and recognized" and "dissemination of work," which were within the career satisfaction organizing theme. The extrinsic organizing themes of advancement and compensation were described as less important contributors to an individual's sense of career success. Ambivalence toward the "academic value of clinical work," "scholarship," and especially "promotion" represented unexpected themes.

CONCLUSIONS: The future of academic hospital medicine is predicated upon faculty finding career success. Clinicianeducator hospitalists view some traditional markers of career advancement as relevant to success. However, earlycareer faculty question the importance of some traditional external markers to their personal definitions of success. This work suggests that the self-concept of career success is complex and may not be captured by traditional academic metrics and milestones. Journal of Hospital Medicine 2018;13:372-377. Published online first January 19, 2018. (O2018 Society of Hospital Medicine

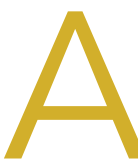

cademic hospital medicine is a young specialty, with most faculty at the rank of instructor or assistant professor. ${ }^{1}$ Traditional markers of academic success for clinical and translational investigators emphasize progressive, externally funded grants, achievements in basic science research, and prolific publication in the peer-reviewed literature. ${ }^{2}$ Promotion is often used as a proxy measure for academic success.

Conceptual models of career success derived from nonhealthcare industries and for physician-scientists include both extrinsic and intrinsic domains. ${ }^{3,4}$ Extrinsic domains of career success include financial rewards (compensation) and progres-

\footnotetext{
*Address for correspondence: Ethan Cumbler MD, FHM, FACP, University of Colorado School of Medicine, 12401 E. 17th Ave., Mail Stop F782, Aurora, CO 80045; Telephone: 720-848-4289; Fax: 720-848-4293; E-mail: Ethan.Cumbler@ ucdenver.edu
}

Received: May 24, 2017; Revised: July 26, 2017; Accepted: August 6, 2017

(c) 2018 Society of Hospital Medicine DOI 10.12788/jhm.2924 sion in hierarchical status (advancement). ${ }^{3,4}$ Intrinsic domains of career success include pleasure derived from daily work (job satisfaction) and satisfaction derived from aspects of the career over time (career satisfaction). 3,4

Research is limited regarding hospitalist faculty beliefs about career success. A better understanding of hospitalist perspectives can inform program development to support junior faculty in academic hospital medicine. In this phenomenological, qualitative study, we explore the global concept of career success as perceived by early-career clinician-educator hospitalists.

\section{METHODS}

\section{Study Design, Setting, and Participants}

We conducted interviews with hospitalists from 3 academic medical centers between May 2016 and October 2016. Purposeful sampling was used. ${ }^{5}$ Leaders within each hospital medicine group identified early-career faculty with approximately 2 to 5 years in academic medicine with a rank of instructor or assistant professor at each institution likely to self-identify as clinician-educators for targeted solicitation to enroll. Additional subjects 
were recruited until thematic saturation had been achieved on the personal definition of career success. Participants received disclosure and consent documents prior to enrollment. No compensation was provided to participants. This study was approved by the Colorado Multiple Institutional Review Board.

\section{Interview Guide Development and Content}

The semistructured interview format was developed and validated through an iterative process. Proposed questions were developed by study investigators on the basis of review of the literature on career success in nonhealthcare industries and academic hospitalist promotion. The questions were assessed for content validity through a review of interview domains by an academic hospitalist program director (R.P.). Cognitive interviewing with 3 representative academic hospitalists who were not part of the study cohort was done as an additional face-validation step of the question probe structure. As a result of the cognitive interviews, 1 question was eliminated, and a framework for clarifications and answer probes was derived prior to the enrollment of the first study subject. No changes were made to the interview format during the study period.

\section{Data Collection}

The principal investigator (E.C.) performed all interviews by using the interview tool consisting of 7 demographic questions and 11 open-ended questions and exploring aspects of the concept of career success. The initial open-ended question, "How would you personally define career success as an academic hospitalist at this stage in your career?" represented the primary question of interest. Follow-up questions were used to better understand responses to the primary question. All interviews were audio recorded, deidentified, and transcribed by the principal investigator. Transcripts were randomly audited by a second investigator (E.Y.) for accuracy and completeness.

\section{Sample Size Determination}

Interviews were continued to thematic saturation. After the first 3 interviews were transcribed, 2 members of the research team (E.C. and P.K.) reviewed the transcripts and developed a preliminary thematic codebook for the primary question. Subsequent interviews were reviewed and analyzed against these themes. Interviews were continued to thematic saturation, which was defined as more than 3 sequential interviews with no new identified themes. ${ }^{6}$

\section{Data Analysis}

By using qualitative data analysis software (ATLAS.ti version 7; ATLAS.ti Scientific Software Development GmbH, Berlin, Germany), transcriptions were analyzed with a team-based, mixed inductive-deductive approach. An inductive approach was utilized to allow basic theme codes to emerge from the raw text, and thus remaining open to unanticipated themes. Investigators assessed each distinct quote for new themes, confirmatory themes, and challenges to previously developed concepts. Basic themes were then discussed among research team members to determine prominent themes, with basic theme codes added, removed, or combined at this stage of the analysis. Responses to each follow-up question were subsequently assessed for new themes, confirmatory themes, or challenges to previously developed concepts related to the personal definition of career success. A deductive approach was then used to map our inductively generated themes back to the organizing themes of the existing conceptual framework.

\section{RESULTS}

We interviewed hospitalists from the University of Colorado $(n=8)$, University of New Mexico $(n=6)$, and Johns Hopkins University $(n=3)$. Subjects primarily identified as clinician-educators. Ninety-four percent (16 of 17) were at the rank of assistant professor, and subjects had been academic hospitalists an average of 3.1 years. Forty-seven percent (8 of 17) were female, and $12 \%$ identified as underrepresented minorities. Interviews averaged 32 minutes.

\section{Thematic Mapping to Organizing Themes of the Conceptual Model (Table)}

The single most dominant theme, "excitement about daily work" was connected to an intrinsic sense of job satisfaction. Career satisfaction emerged from interviews more frequently than extrinsic organizing themes, such as advancement or compensation. Advancement through promotion was infrequently referenced as part of success, and tenure was never raised despite being available for clinician-educators at 2 of the 3 institutions. Compensation was not referenced in any interviewee's initial definition of career success, although in 1 interview, it came up in response to a follow-up question. The Figure visually represents the relative weighting (shown by the sizes of the boxes) of organizing themes to the early-career hospitalists' self-concepts of career success. Relationships among organizing themes as they emerged from interviews are represented by arrows.

\section{Intrinsic - Job Satisfaction}

With regard to job satisfaction, early-career faculty often invoked words such as "excitement," "enjoyment," and "passionate" to describe an overall theme of "excitement about daily work." A positive affective state created by the nature of daily work was described as integral to the personal sense of career success. It was also strongly associated with perception of sustainability in a hospitalist career.

"I think [career success] would be job satisfaction. ...So, for me, that would be happiness with my job. I like coming to work. I like doing what I do and at the end of the day going home and saying that was a good day. I like to think that would be success at work...is how I would define it."

This theme was also related to a negative aspect often referred to as burnout, which many identified as antithetical to career success. More often, they described success as a heightened state of enthusiasm for the daily work experience.

"I am staying engaged and excited. So, I am not just taking care of patients; I am not just teaching. Having enough excitement from my work to come home and talk about it at dinner. 
TABLE. Themes and Quotes from Hospitalist Interviews

\begin{tabular}{lll}
\hline Organizing Theme & Basic Theme & Representative Quote \\
\hline Job satisfaction & Excitement about daily work & $\begin{array}{l}\text { "Coming in to work every day and [getting] excited about seeing all of the patients, excited about the clinical care, } \\
\text { being excited about teaching my team...that would be successful." }\end{array}$ \\
\cline { 2 - 3 } & $\begin{array}{l}\text { Practices high-quality, high-value care } \\
\text { "I think developing clinical expertise, both through experience and studying, getting to the point where you can take } \\
\text { really excellent care of your patient through expertise would be a sense of success that a lot of academic hospitalists } \\
\text { would strive for." }\end{array}$ \\
\hline Clinical proficiency & "Success for me will [be] both becoming completely comfortable and conversant in my clinical responsibilities." \\
\hline Ambivalence about the value placed on clinical work & $\begin{array}{l}\text { "I remember when I was first starting out in academics and I had a colleague tell me that success in academics is } \\
\text { making money while seeing less patients....and I thought to myself, 'Well the whole reason I went to medical school } \\
\text { was to learn how to take care of and see patients." }\end{array}$ \\
\hline
\end{tabular}

Career satisfaction Respected and recognized

"I would say recognition from my students as a great teacher and recognition of my patients as a great provider. I would say those would be the 2 main components I would associate with academic success."

Dissemination of individuals' work Identifying that you have presented a certain number of workshops or completed a certain number of publications that are allowing one to progress in [his or her] career."

Developing expertise, a niche

"Starting to find a sphere outside of clinical medicine where I am starting to become an expert in something that is related to hospital medicine." "I do think that to be successful in academics in general you need to have something about which you can make yourself an expert or about which you can create content that's novel." rounded would be considered successful in my eyes."

Making a difference, quality improvement

"I would feel more personally successful if I had a few projects where I was making a real difference in patient care and the system in which I work."

Excellence in teaching

"From the educator standpoint, being able to spend more time, or some time, with the residents and maybe being recognized by residents as somebody who is good at teaching them and that they enjoy working with."

"So, to me, success is [feeling] like seeing the lightbulb go on for the learner as you describe why you are doing what you are doing for a patient."

Excellence in multiple professional domains

"I think for me, it is essentially excelling within all of the various different aspects and then hopefully together that meets a role of success."

Diversity of activities

"For me, success in medicine is being able to find that right balance between clinical and nonclinical and still making sure that I am enjoying what I am doing in both of those arenas given the time that I have."

Excellence in leadership

"For me, what is really important is when I attain that level of leadership that I also still practice, to some degree, the fundamentals within whatever genre that I am leading. ... I genuinely believe a leader should not only be in touch with the frontlines but should know what the frontlines are doing."

Creating innovative programs

"I've started a program within the residency that was a novel new program. So, I got to...start a program."

Relationships

"I guess more personally it means...cultivating relationships with colleagues who would empower you to move your career forward."

Autonomy

"Satisfaction...I think it means I am able to pursue these things in the manner that I want to pursue them."

Achieving personal best

"Success in general is defined as a person doing all that they can within their own power, knowing that they did everything that they could to succeed. The outcome is not the definition of success."

Project completion

"I would feel some sense of success with finishing some quality-improvement and research projects."

Progressive improvement

"I also realize how great it is to continue to gain new skills and feel like you're developing in that way."

Absence of burnout

"Having enough variety in what I am doing to feel that I am not getting burned out."

Ambivalence about finding success

"I don't feel much sense of success, either historically or... there is not much that I consider would make me feel successful in the future."

Continued on page 375

To enjoy my days off but at the same time being excited to get back to work."

This description of passion toward the work of being a hospitalist was often linked to a sense of deeper purpose found through the delivery of clinical care and education of learners.
"I really feel that we have the opportunity to very meaningfully and powerfully impact people's lives, and that to me is meaningful. ...That's value. ...That's coming home at the end of the day and thinking that you have had a positive impact."

The interviews reflected that core to meaningful work was a 
TABLE. Themes and Quotes from Hospitalist Interviews (continued)

\begin{tabular}{|c|c|c|}
\hline Organizing Theme & Basic Theme & Representative Quote \\
\hline \multirow[t]{8}{*}{ Advancement } & Promotion (and ambivalence about academic promotion) & "People who have successfully gone up for promotion, I look at that definitely as a marker of success." \\
\hline & & $\begin{array}{l}\text { "I think a lot of people would consider promotion to be a sense of success, although I am not sure it is really as } \\
\text { prevalent as it seems that it would be." }\end{array}$ \\
\hline & $\begin{array}{l}\text { Publications, scholarship (and ambivalence about } \\
\text { publications, scholarship) }\end{array}$ & $\begin{array}{l}\text { "Thinking about the things the promotions committee... I guess we need to publish, be involved in various different } \\
\text { committees, or show scholarship..." }\end{array}$ \\
\hline & & $\begin{array}{l}\text { "For me personally, I have less of an emphasis on research and some of the more... scholarly practice of medicine, } \\
\text { doing research and the writing of papers and things like that. Although I certainly view some of that as part of career } \\
\text { success, for me, success is more about finding an activity that's rewarding and meaningful and that I would want to } \\
\text { devote my life to doing." }\end{array}$ \\
\hline & Independent research funding & $\begin{array}{l}\text { "Part of my definition of career success would be being able to secure that funding then being productive in the } \\
\text { research that I am able to do with that time." }\end{array}$ \\
\hline & Professional progression & $\begin{array}{l}\text { "Meeting the milestones...that are probably defined at the beginning of one's career and then revisited... being able } \\
\text { to identify that you have actually met those discrete milestones." }\end{array}$ \\
\hline & Protected nonclinical time & "Earning some protected time to work a little bit less on clinical duties." \\
\hline & Obtaining a leadership role & "I think it would require me to basically have a leadership role." \\
\hline Compensation & Income-matching needs & $\begin{array}{l}\text { "Having the ability to not worry about money would be success for my career. Obviously, not running around buying } \\
\text { Christian Louboutin shoes or whatever but... being comfortable in my life." }\end{array}$ \\
\hline
\end{tabular}

NOTE: The compensation theme was not spontaneously elicited from the primary question, but it was identified in 1 interview during follow-up questions.

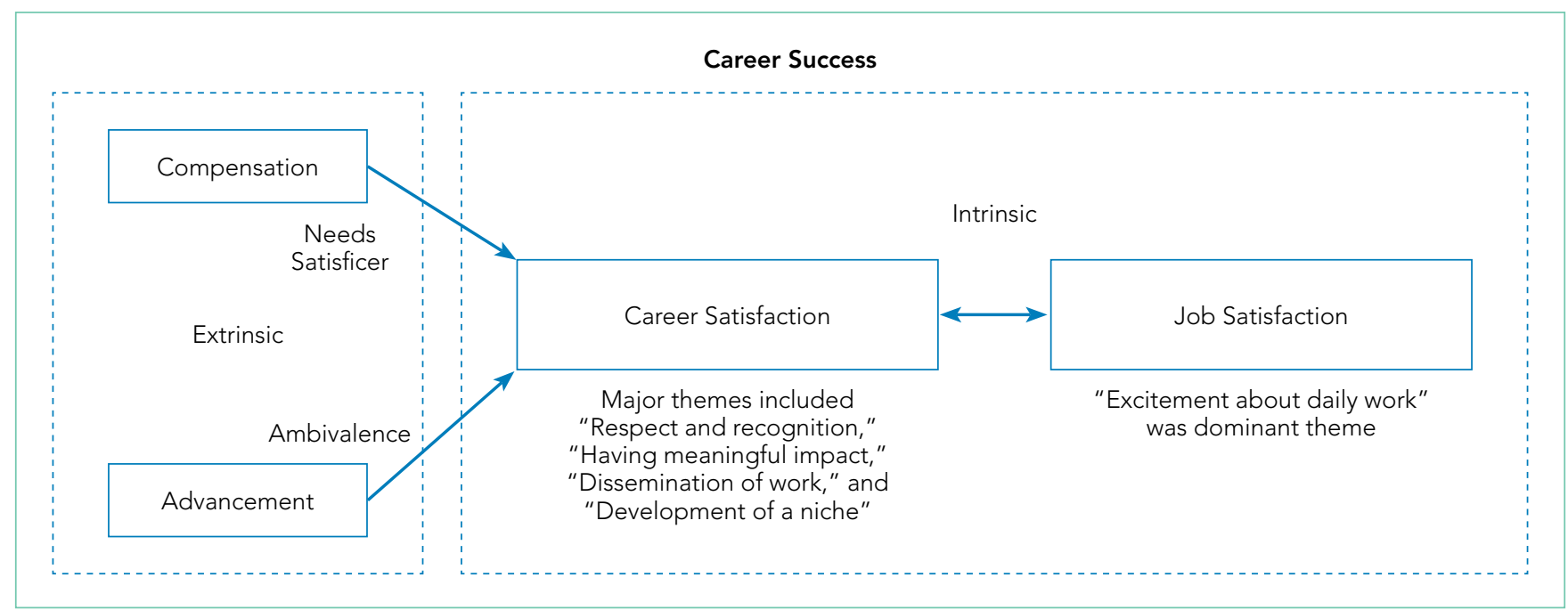

FIG. Organizing Themes

sense of personal efficacy as a clinician, which was reflected in the themes of clinical proficiency and practicing high-quality care.

"I think developing clinical expertise, both through experience and studying. Getting to the point to where you can take really excellent care of your patient through expertise would be a sense of success that a lot of academic hospitalists would strive for."

\section{Intrinsic - Career Satisfaction}

Within career satisfaction, participants described that "being respected and recognized" and "dissemination of work" were important contributors to career success. Reputation was frequently referenced as a measure of career success. Reputation was defined by some in a local context of having the respect of learners, peers, and others as a national renown. As a prerequisite for developing a reputation beyond the local academic environment, dissemination of work was often referenced as an important component of satisfaction in the career. This dissemination extended beyond peer-reviewed publications and included other forms of scholarship, presentations at conferences, and sharing clinical innovations between hospitals.

"For me personally, I have less of an emphasis on research and some of the more, I don't want to say 'academic' because I think education is academic, but maybe some of the more scholarly practice of medicine, doing research and the writing of papers and things like that, although I certainly view some of that as a part of career success." 
Within career satisfaction, participants also described a diverse set of themes, including progressive improvement in skills, developing a self-perception of excellence in 1 or more arenas of academic medicine, leadership, work-life integration, innovation, and relationships. The concept of developing a niche, or becoming an expert in a particular domain of hospital medicine, was frequently referenced.

"I think part of [success] is 'Have they identified a niche?' Because I think if you want to be in an academic center, as much as I value teaching and taking care of patients, I think one of the advantages is the opportunity to potentially identify an area of expertise."

Participants frequently alluded to the idea that the most important aspects of career satisfaction are not static phenomena but rather values that could evolve over the course of a career. For instance, in the early-career, making a difference with individual learners or patients could have greater valence, but as the career progressed, finding a niche, disseminating work, and building a national reputation would gain importance to a personal sense of career satisfaction.

\section{Extrinsic - Advancement}

Promotion was typically referenced when discussing career success, but it was not uniformly valued by early career hospitalists. Some expressed significant ambivalence about its effect on their personal sense of career success. Academic hospitalists identified a number of organizations with definitions of success that influence them. Definitions of success for the university were more relevant to interviewees compared to those of the hospital or professional societies. Interviewees were able to describe a variety of criteria by which their universities define or recognize career success. These commonly included promotion, publications and/or scholarship, and research. The list of factors perceived as success by the hospital were often distinct from those of the university and included cost-effective care, patient safety, and clinical leadership roles.

Participants described a sense of internal conflict when external-stakeholder definitions of success diverged from internal motivators. This was particularly true when this divergence led academic hospitalists to engage in activities for advancement that they did not find personally fulfilling. Academic hospitalists recognized that advancement was central to the concept of career success for organizations even if this was not identified as being core to their personal definitions of success.

"I think that for me, the idea of being promoted and being a leader in the field is less important to me than...for the organization."

Hospitalists expressed that objective markers, such as promotion and publications, were perceived as more important at higher levels of the academic organization, whereas more subjective aspects of success, aligned with intrinsic personal definitions, were more valued within the hospital medicine group.

\section{Extrinsic - Compensation}

Compensation was notable for its absence in participants' discussion of career success. When asked about their definitions of career success, academic hospitalists did not spontaneously raise the topic of compensation. The only mention of compensation was in response to a question about how personal and external definitions of career success differ.

\section{Unexpected Findings}

While it was almost universally recognized by participants as important, ambivalence toward the "academic value of clinical work," "scholarship," and especially "promotion" represented an unexpected thematic family.

"I can't quite get excited about a title attached to my name or the number of times my name pops up when I enter it into PubMed. My personal definition is more... where do I have something that I am interested [in] that someone else values. And that value is not shown as an associate professorship or an assistant professorship next to my name. ...When you push me on it, you could call me clinical instructor forever, and I don't think I would care too much."

The interaction between work and personal activities as representing complementary aspects of a global sense of success was also unexpected and ran contrary to a simplistic conception of work and life in conflict. Academic hospitalists referenced that the ability to participate in aspects of life external to the workplace was important to their sense of career success. Participants frequently used phrases such as "work-life balance" to encompass a larger sense that work and nonwork life needed to merge to form a holistic sense of having a positive impact.

"Personal success is becoming what I have termed a 'man of worth.' I think [that is] someone who feels as though they make a positive impact in the world. Through both my career, but I guess the things that I do that are external to my career. Those would be defined by being a good husband, a good son, a philanthropist out in the community...sometimes, these are not things that can necessarily go on a [curriculum vitae]."

\section{Conflict Among Organizing Themes}

At times, academic hospitalists described a tension between day-to-day job satisfaction and what would be necessary to accomplish longer-term career success in the other organizing themes. This was reflected by a sense of trade-off. For instance, activities that lead to some aspects of career satisfaction or advancement would take time away from the direct exposure to learners and clinical care that currently drive job satisfaction.

"If the institution wanted me to be more productive from a research standpoint or...advocate that I receive funding so I could buy down clinical time and interactions I have with my students and my patients, then I can see my satisfaction going down."

Many described a sense of engaging in activities they did not find personally fulfilling because of a sense of expectation that those activities were considered successful by others. Some described a state in which the drive toward advancement as an extrinsic incentive could come at the expense of the intrinsic rewards of being an academic hospitalist. 


\section{DISCUSSION}

Career success has been defined as "the positive psychological or work-related outcomes or achievements one accumulates as a result of work experiences." $4,7,8$ Academic career success for hospitalist faculty isn't as well defined and has not been examined from the perspectives of early-career clinician-educator hospitalist faculty themselves.

The themes that emerged in this study describe a definition of success anchored in the daily work of striving to become an exceptional clinician and teacher. The major themes included (1) having excitement about daily work, (2) having meaningful impact, (3) development of a niche (4) a sense of respect within the sphere of academic medicine, and (5) disseminating work.

Success was very much internally defined as having a positive, meaningful impact on patients, learners, and the systems in which they practice. The faculty had a conception of what promotion committees value and often internalized aspects of this, such as developing a national reputation and giving talks at national meetings. Participants typically self-identified as clinician-educators, and yet dissemination of work remained an important component of personal success. While promotion was clearly identified as a marker of success, academic hospitalists often rejected the supposition of promotion itself as a professional goal. They expressed hope, and some skepticism, that external recognition of career success would follow the pursuit of internally meaningful goals.

While promotion and peer-reviewed publications represent easily measured markers often used as proxies for individual career and programmatic success, our research demonstrates that there is a deep well of externally imperceptible influences on an individual's sense of success as an academic hospitalist. In our analysis, intrinsic elements of career success received far greater weight with early-career academic hospitalists. Our findings are supported by a prior survey of academic physicians that similarly found that faculty with $\geq 50 \%$ of their time devoted to clinical care placed greater career value in patient care, relationships with patients, and recognition by patients and residents compared to national reputation. ${ }^{9}$ Similar to our own findings, highly clinical faculty in that study were also less likely to value promotion and tenure as indicators of career success. $^{9}$

The main focus of our questions was how early-career faculty define success at this point in their careers. When asked to extrapolate to a future state of career success, the concept of progression was repeatedly raised. This included successive promotions to higher academic ranks, increasing responsibility, titles, leadership, and achieving competitive roles or awards. It also included a progressively increasing impact of scholarship, growing national reputation, and becoming part of a network of accomplished academic hospitalists across the country. Looking forward, our early-career hospitalists felt that long-term career success would represent accomplishing these things and still being able to be focused on being excellent clinicians to patients, having a work-life balance, and keeping joy and excitement in daily activities.

Our work has limitations, including a focus on early-career clinician-educator hospitalists. The perception of career success may evolve over time, and future work to examine perceptions in more advanced academic hospitalists would be of interest. Our work used purposeful sampling to capture individuals who were likely to self-identify as academic clinician-educators, and results may not generalize to hospitalist physician-scientists or hospitalists in community practices.

Our analysis suggests that external organizations influence internal perceptions of career success. However, success is ultimately defined by the individual and not the institution. Efforts to measure and improve academic hospitalists' attainment of career success should attend to intrinsic aspects of satisfaction in addition to objective measures, such as publications and promotion. This may provide a mechanism to address burnout and improve retention. As important as commonality in themes is the variation in self-definitions of career success among individuals. This suggests the value of inquiry by academic leadership in exploring and understanding what success is from the individual faculty perspective. This may enhance the alignment among personal definitions, organizational values, and, ultimately, sustainable, successful careers.

Disclosure: The authors have nothing to disclose.

\section{References}

1. Harrison R, Hunter AJ, Sharpe B, Auerbach AD. Survey of US Academic Hospitalist Leaders About Mentorship and Academic Activities in Hospitalist Groups. J Hosp Med. 2011;6(1):5-9.

2. Buddeberg-Fischer B, Stamm M, Buddeberg C, Klaghofer R. Career-Success Scale. A New Instrument to Assess Young Physicians Academic Career Steps. BMC Health Serv Res. 2008;8:120.

3. Rubio DM, Primack BA, Switzer GE, Bryce CL, Selzer DL, Kapoor WN. A Comprehensive Career-Success Model for Physician-Scientists. Acad Med. 2011;86(12):1571-1576

4. Judge TA, Cable DM, Boudreau JW, Bretz RD. An empirical investigation of the predictors of executive career success (CAHRS Working Paper \#94-08). Ithaca, NY: Cornell University, School of Industrial and Labor Relations, Center for Advanced Human Resource Studies. 1994. http://digitalcommons.ilr. cornell.edu/cahrswp/233. Accessed November 27, 2017.

5. Palinkas LA, Horwitz SM, Green CA, Wisdom JP, Duan N, Hoagwood K. Purposeful sampling for qualitative data collection and analysis in mixed method implementation research. Adm Policy Ment Health. 2015;42(5):533-544.

6. Francis JJ, Johnston M, Robertson C, et al. What is an adequate sample size? Operationalising data saturation for theory-based interview studies. Psychol Health. 2010;25(10):1229-1245.

7. Abele AE, Spurk, D. The longitudinal impact of self-efficacy and career goals on objective and subjective career success. J Vocat Behav. 2009;74(1):53-62.

8. Seibert SE, Kraimer ML. The five-factor model of personality and career success. J Vocat Behav. 2011;58(1):1-21.

9. Buckley, LM, Sanders K, Shih M, Hampton CL. Attitudes of Clinical Faculty About Career Progress, Career Success, and Commitment to Academic Medicine: Results of a Survey. Arch Intern Med. 2000;160(17):2625-2629. 